\title{
OPTIMAL SCHEDULING MODELS FOR FERRY COMPANIES UNDER ALLIANCES
}

\author{
Shangyao Yan \\ Professor, Department of Civil Engineering, National Central University, Chungli, Taiwan 32054, R.O.C., \\ t320002@cc.ncu.edu.tw \\ Chia-Hung Chen \\ Ph.D. candidate, Department of Civil Engineering, National Central University, Chungli, Taiwan 32054, R.O.C. \\ Hsin-Yen Chen \\ Undergraduate, Department of Civil Engineering, National Central University, Chungli, Taiwan 32054, R.O.C. \\ Tze-Chiang Lou \\ Ph.D. candidate, Department of Civil Engineering, National Central University, Chungli, Taiwan 32054, R.O.C.
}

Follow this and additional works at: https://jmstt.ntou.edu.tw/journal

Part of the Business Commons

\section{Recommended Citation}

Yan, Shangyao; Chen, Chia-Hung; Chen, Hsin-Yen; and Lou, Tze-Chiang (2007) "OPTIMAL SCHEDULING MODELS FOR FERRY COMPANIES UNDER ALLIANCES," Journal of Marine Science and Technology. Vol. 15: Iss. 1, Article 8. DOI: $10.51400 / 2709-6998.2033$

Available at: https://jmstt.ntou.edu.tw/journal/vol15/iss1/8

This Research Article is brought to you for free and open access by Journal of Marine Science and Technology. It has been accepted for inclusion in Journal of Marine Science and Technology by an authorized editor of Journal of Marine Science and Technology. 


\section{OPTIMAL SCHEDULING MODELS FOR FERRY COMPANIES UNDER ALLIANCES}

\section{Acknowledgements}

This research was supported by a grant from the National Science Council of Taiwan. We thank the two ferry companies for providing the test data as well as their valuable opinions. 


\title{
OPTIMAL SCHEDULING MODELS FOR FERRY COMPANIES UNDER ALLIANCES
}

\author{
Shangyao Yan*, Chia-Hung Chen**, Hsin-Yen Chen*** and Tze-Chiang Lou**
}

Key words: ferry, alliance, scheduling, multiple commodity network flow problem.

\section{ABSTRACT}

Ferry companies in Taiwan increasingly ally themselves with other ferry companies as a means of forming more complete networks, to operate more efficiently. The more complex ferry fleet routing and scheduling processes are not only important in each company's operations, but also have a bearing on the alliance. In this research, we employ network flow techniques to construct several coordinated scheduling models to help solve for the most satisfactory schedules for the allied ferry companies. Finally, we perform a case study based on real operating data from two Taiwan ferry companies to evaluate the models. The preliminary results show that the model could be useful for this type of situation.

\section{INTRODUCTION}

In recent years, tourism has developed rapidly in Taiwan. For example, the mass rapid transit system has allowed Danshui to develop into a popular amusement area. To enhance this development, the government has recently promoted an Inland River Blue Highway plan, aimed at producing specialized tours, in order to offer more service options to local tourists. Given these circumstance, the ferry companies have striven to improve their operations. Of all the factors, ferry fleet routing/scheduling has been the most important focus of ferry companies, because this not only affects ferry boat usage efficiency, the establishment of the timetable, and maintenance and crew scheduling, but is also essential to a ferry company's profitability and its level of service.

Most ferry companies in Danshui currently use a trial-and-error process for ferry fleet routing and sched-

Paper Submitted 03/08/06, Accepted 05/12/06. Author for Correspondence: Shangyao Yan. E-mail: t320002@cc.ncu.edu.tw.

*Professor, Department of Civil Engineering, National Central University, Chungli, Taiwan 32054, R.O.C.

**Ph.D. candidate, Department of Civil Engineering, National Central University, Chungli, Taiwan 32054, R.O.C.

***Undergraduate, Department of Civil Engineering, National Central University, Chungli, Taiwan 32054, R.O.C. uling practices. The planners adjust the drafted timetable and the ferry fleet routes/schedules by considering the number of available ferry boats, their average operating speed, the turn-around time at the ports, the ferry fleet balance at each port, and the related cost/revenue of ferry boat movements between ports. Note that the timetable is typically designed by experience, in accordance with the projected demand, the market share, and the given right of waterway. This process is iterated manually, without optimization from a systemic perspective. After adjustments, the schedule is then sent to be checked for ferry boat maintenance and crew scheduling, with possible minor revisions. Such an approach is less efficient when service networks grow, and could possibly result in an inferior solution.

Much research has already been devoted to ship routing and shipment scheduling problems, by the marine industry as well as in academic fields [3, 4, 7-9, 13-15]. Our survey of the above research on shipment scheduling indicates that the focus has been on single carrier cargo transportation, which is fundamentally different from Taiwan's Inland River passenger transportation. Passengers in particular are more time sensitive than cargo. Moreover, shipment scheduling belongs to the long-haul type of transportation, which is fundamentally different. In addition, the fast growth of the Inland River market in this area, forces the ferry companies to place strategic emphasis on the growth of Inland River transportation, to improve their operating performance, and to provide better services.

Actually, there are hundreds of different types of alliances in the transportation industries, ranging from agreements for specific routes to full mergers. The setting of a good coordinated ferry schedule can not only enhance the operating performance of the allied ferry companies, but can also act as a useful reference for ferry company alliance decision-making. For example, if it is difficult to develop new OD service ferry trips, then two ferry companies can enter into a complementary alliance, linking existing partial trips to form a new more complete complementary trip and to offer new OD services. An effective coordinated scheduling model would help these companies find the most 
satisfactory ferry fleet routes and timetables.

At this point in time, however, ferry companies trying to coordinate alliance schedules, generally use a trial-and-error process for ferry fleet routing and scheduling formulation. Schedules are reciprocally iterated, constructed and evaluated, manually and independently, without optimization from a systemic perspective. Only after all this, do the allies check to see whether their schedules are mutually suitable. If they are not, then each schedule must be modified further. The process is repeated until satisfactory results are obtained. It is easy to see that such an approach is neither effective nor efficient, especially when the ferry network is large. Inferior solutions can be the result.

How to simultaneously determine a good coordinated ferry schedule that satisfies each company in the alliance is difficult. Recently much academic research has been devoted to the solving of alliance problems [2, $5,6,10-12,16,21]$. We have not found any research in this literature that covers both ferry fleet routing and scheduling under alliances. In addition, the literature main focus has been on air transportation, which makes it difficult to apply to the ferry alliance scheduling problem, and to integrate ferry alliances, ferry fleet routing and timetable setting, in short-term operations.

In this research, we develop several coordinated scheduling models that combine ferry company alliances, ferry fleet routing and timetable setting to help the participating ferry companies solve for the most satisfactory ferry fleet routes and timetables for short-term operations under parallel and complementary alliances, given the projected OD demand, ferry fleet size, and related cost data. The proposed models are expected to be good planning tools for the allied ferry companies. If the given inputs are changed, or the obtained results do not reflect the inputs, then the models can be suitably modified and rerun until satisfactory results are acquired. For simplicity, we focus primarily on single-ferry fleet routing and scheduling but the models could be extended to multi-ferry fleet operations. Furthermore, for simplicity of modeling, two ferry companies (Ferry companies A and B) are used as examples. Although the scheduling process is, in practice, related to the ferry boat maintenance and the crew scheduling processes, these processes are carried out after ferry fleet routing and scheduling. In particular, maintenance and crew constraints are rather flexible in practice, for the ferry companies studied in this research. In a few cases the routes and schedules may have to be slightly modified to meet maintenance or crew scheduling issues. To facilitate problem solving, we therefore exclude these constraints in our modeling. The rest of this paper is organized as follows: First, we introduce the models. Then, nu- merical tests are performed to evaluate the models. Finally, we offer some conclusions.

\section{MODELING APPROACH}

Traditionally, ferry companies have used draft timetables as an essential medium for ferry fleet routing and timetable setting. This not only involves too much subjective judgment in the process, but also reveals the difficulty of systematically managing the interrelation between supply and demand. To improve the difficulty of drafting multiple-stop timetables for passenger transport, Yan and Tseng [18] suggested using a network model, containing fleet flow networks and passenger flow networks. The model can directly manage the interrelationships between passenger trip demands and flight supplies, so as to more effectively assist carriers' scheduling. Such an approach has recently been applied to other problems $[1,17]$. Referring to Yan and Tseng [18], a time-space network technique is applied to construct several coordinated ferry fleet routing and scheduling models for the purpose of maximizing the ferry companies' total profit. For ease of modeling, a basic model is created first, followed by several strategic models. The major elements in the modeling, including the ferry-flow networks, the passenger-flow networks, and the mathematical formulation, are as follows.

\section{Ferry-flow networks}

A network, as shown in Figures 1 or 2, for singleferry fleet routing is established for each company, within the specified time period (one day in this study) and location. Note that for ease of reading, the thin dotted arrows indicate the ally's fleet-flow network but such dotted arrows do not really exist in the ferry-flow network. The horizontal axis represents the port locations; the vertical axis stands for the time duration. All available ports are included. The two major components in the network are "nodes" and "arcs." Each node represents a specific port and a specific time, while each arc represents an activity for a ferry boat, such as a service, a berthing period, or an overnight stay. The arc flows express the flow of ferry fleet in the network. Three types of arcs are defined below.

\section{(1) Service arc}

A service arc represents a trip connecting two different ports. Different service arc densities may be set for different periods or port pairs, for peak/ non-peak hours or the demands for each port pair. For example, in current practices the designated trip frequency is five minutes for peak periods and one ferry 


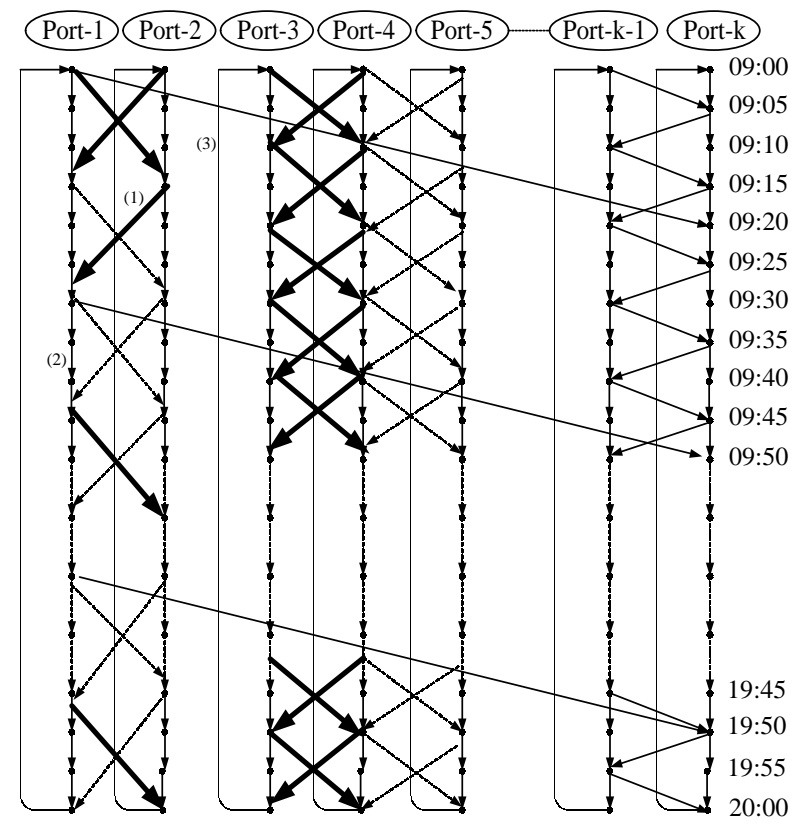

(1) Service arc (2) Berthing arc (3) Cycle arc

Fig. 1. Ferry-flow network of Ferry A.

trip per half hour for non-peak hours. Each service arc contains information about the departure time, the departure port, the arrival time, the arrival port and the operating cost. The time block for a ferry trip is calculated as from the time when the ferry boat is prepared for this trip to the time when this trip is finished. Basically, it includes an investigation time prior to departure, time for fuelling, passenger embarkation and debarkation, and the actual trip time. The arc cost is thus the ferry boat operating cost. The arc flow is a binary variable denoting the number of ferry boats ( 0 or 1$)$ that serve the associated ferry trip. The arc flow's upper bound is one, meaning that a trip can be served at most once. The arc flow's lower bound is zero, implying that no boat serves this trip. In addition, the departure interval at the same port is adjustable to meet each company's operating requirements.

To design service arcs for parallel/complementary alliances, the following two points should also be considered.

\section{A. Parallel alliance}

A parallel alliance refers to the collaboration of two ferry companies with the same routes in their networks. In a parallel alliance, the companies together service a trip. Typically one company charges a fee to its ally for serving their passengers. This means that a side constraint should be set for the trip, ensuring that

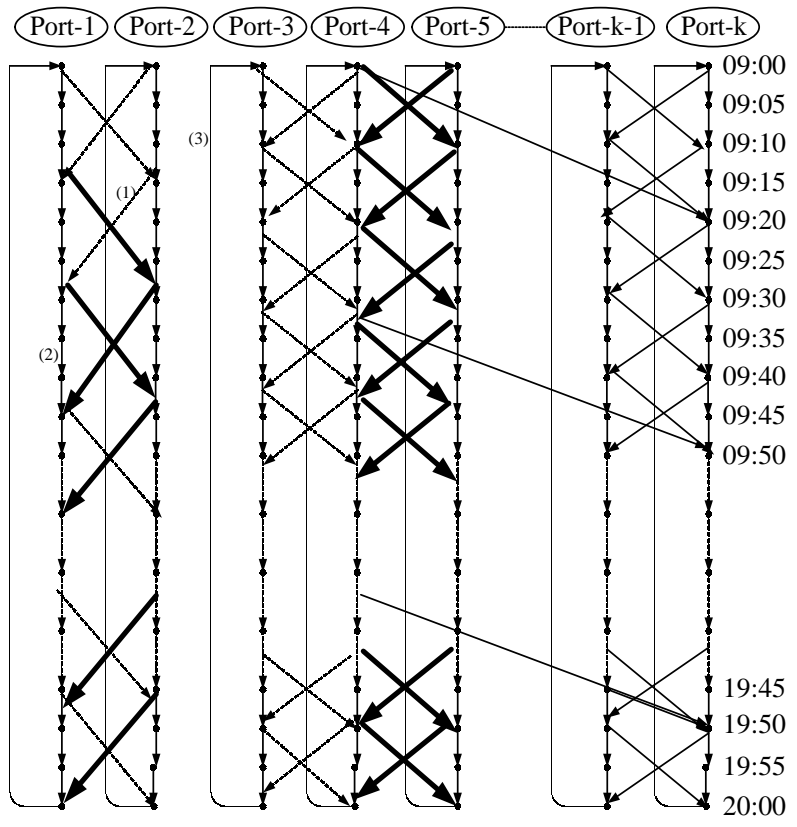

(1) Service arc (2) Berthing arc (3) Cycle arc

Fig. 2. Ferry-flow network of Ferry B.

the arc flows associated with the same service arc in the two networks are at most one. As shown in Figure 1, the thick arrows (served by Ferry company A) and the thin dotted arrows (served by Ferry company B) represent trips connecting port 3 and port 4 . Similarly, as shown in Figure 2, service arcs are designed to connect port 4 and port 3 . The two types of trips have the same origin and destination but are separately distributed.

\section{B. Complementary alliance}

A complementary alliance refers to a situation where two ferry companies have linked their existing partial networks to form a new more complete complementary network. In other words, traffic is fed to each other. In a complementary alliance, the companies both form a ferry trip to serve a new OD demand. As shown in Figure 1, the thick arrows (served by Ferry company A) and the thin dotted arrows (served by Ferry company B) represent the trips connecting port 6 and port $k$. Ferry company A is first (port 6 to port k-1) and Ferry company B is second (port k-1 to port k), or Ferry company B is first (port k to port k-1) and Ferry company A is second (port k-1 to port 6). Similarly, the service arcs in Figure 2 are designed to connect port 6 and port $\mathrm{k}$.

\section{(2) Berthing arc}

A berthing arc represents the holding of ferry 
boats at a port in a time window. The arc cost denotes the holding expenses incurred. The arc flow's upper bound is the anchorage capacity (or infinity, if the capacity is large). This indicates the maximum number of ferry boats that can be held at this port during a specific time window. The arc flow's lower bound is zero, implying that no ferry boat is held at this port in this time window.

\section{(3) Cycle arc}

A cycle arc represents the continuity between two consecutive planning periods. It connects the end of one period to the beginning of the next period for each port. Such a technique ensures that fleet routes and schedules rotate regularly, which makes them easier to implement in practice. Note that, without cycle arcs, routes may not rotate regularly and deadheading of ferry boats could occur, which would increase the operating cost. Similar approaches have been applied in other scheduling problems [19]. The arc cost is the cost of holding a ferry boat overnight, and is similar to the berthing arc cost but with the addition of an overnight charge. The upper bound and lower bound of the arc flow are set the same as those of the berthing arcs.

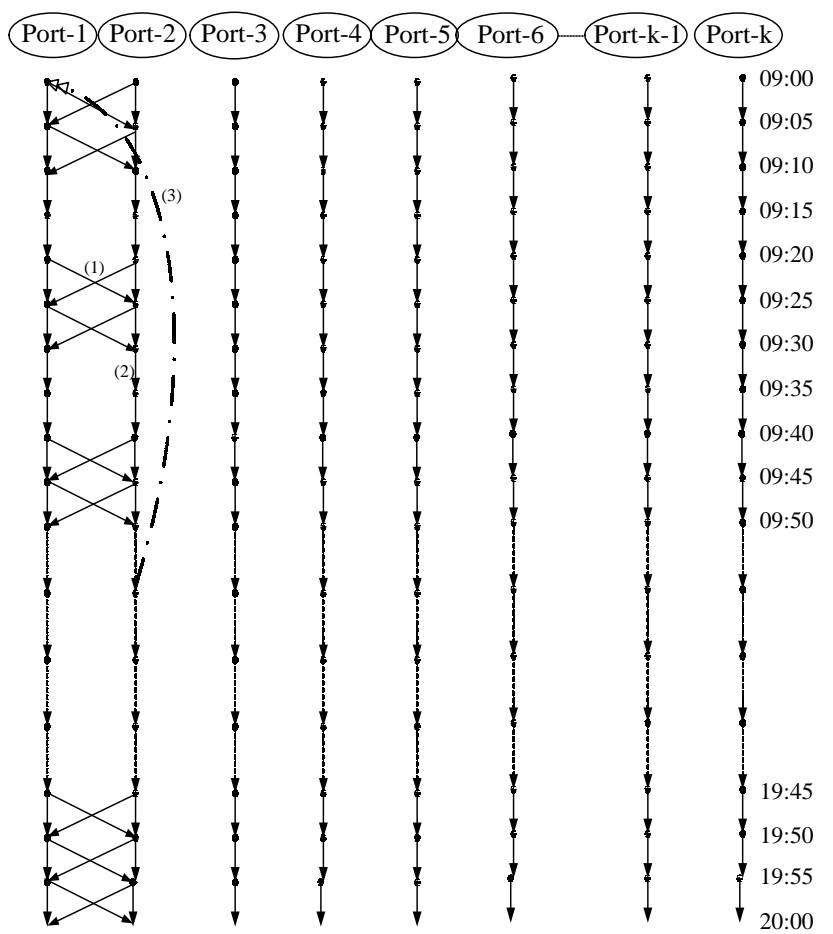

(1) Transport arc (2) Stay arc (3) Demand arc

Fig. 3. Individual passenger-flow network for Ferry company A (OD pair: 1->2)

\section{Passenger-flow networks}

The time-space network technique is applied to model passenger movement at certain times and locations, for each ferry company. Each passengerflow network represents a specific OD pair from the origin-destination table (known as the OD table). A set of passenger-flow networks associated with the ODs are constructed for each ferry company. In particular, three types of passenger-flow networks, with a similar structure, are created for each ferry company, including individual, parallel and complementary alliance networks, as shown in Figures 3, 4 and 5, respectively. An individual passenger-flow network plans the transportation of an OD's passengers, by only its own ferry/ ferry trips in terms of time and space. A parallel alliance passenger-flow network plans the transportation of an OD's passengers, by its and its allied ferry company's ferry/ferry trips, but on the same route. A complementary alliance passenger-flow network plans the transportation of a new OD's passengers, via its ferry trips and its allied ferry company's ferry trips, in each existing partial network, to form a new complementary network. To facilitate problem solving these networks are designed to be symmetrical to the ferry-flow networks. Since the networks for Ferry companies A

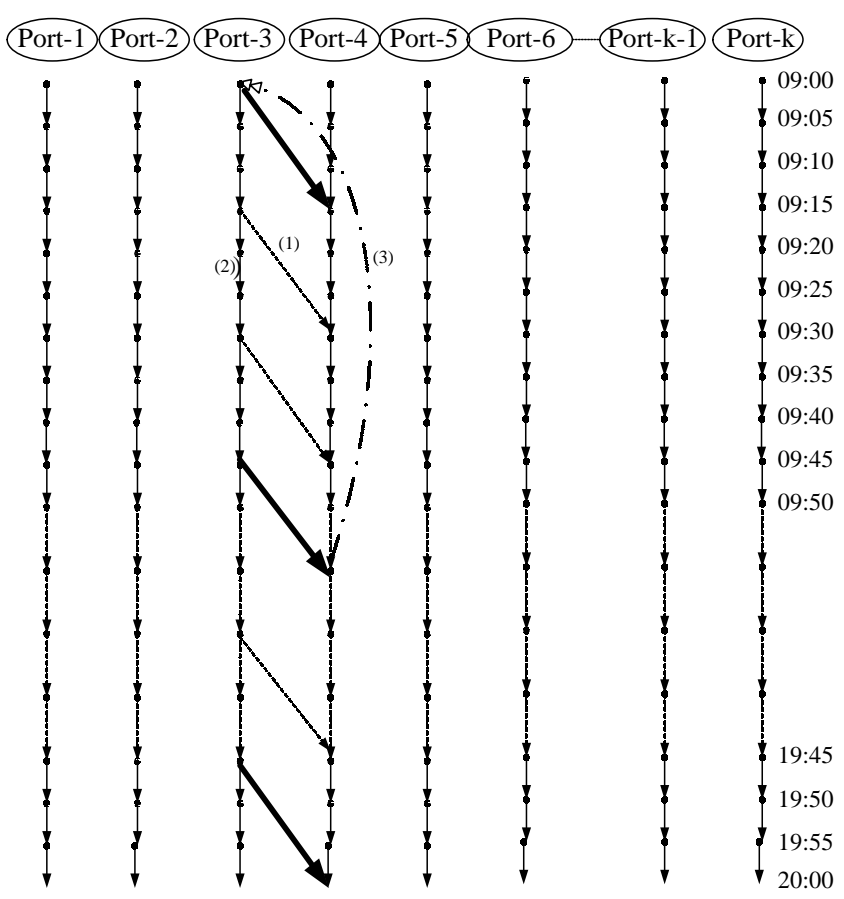

(1) Transport arc (2) Stay arc (3) Demand arc

Fig. 4. Parallel alliance passenger-flow network for Ferry company A (OD pair: 3->4) 


Port-1 Port-2 Port-3 Port-4 Port-5) Port-6) Port-k-1) Port-k

(1) Transport arc (2) Stay arc (3) Demand arc

Fig. 5. Complementary alliance passenger-flow network (OD pair: 6->k)

and $\mathrm{B}$ are similar, to save space, we only show the networks for Ferry company A. The horizontal and vertical axes are the same as those in the ferry-flow networks. Here, a node also represents a port at a specific time, but an arc designates an activity showing passenger movement. There are three types of arcs in each type of passenger-flow network. They are defined below.

\section{(1) Transport arc}

A transport arc represents the transportation of passengers from one port to another. The trip is served by either the original ferry company or its ally. The transportation time is the same as the corresponding time block for the associated ferry trip in the ferry-flow network. The arc flow's upper bound is the ferry boat capacity (with perhaps a planning load factor), meaning that the maximum flow in the arc is the loading capacity. The arc flow's lower bound is zero, indicating that no passenger from the corresponding OD is delivered on the associated ferry trip. In addition to the above common characteristics, there are attributes specific to each type of passenger-flow network, described as follows:

The arc cost for an individual passenger-flow network, as shown in Figure 3, is a variable cost for serving a passenger. In a parallel alliance passengerflow network, as shown in Figure 4, the associated transport arc cost for a ferry trip served by the individual ferry company, is a variable cost for serving a passenger; when the trip is served by the allied ferry company, the associated transport arc cost is the cost that the ferry company has to pay its ally (usually negotiated between the two ferry companies), to compensate for the transport of a passenger. The arc costs for a complementary alliance passenger-flow network, as shown in Figure 5, are set similar to the arc costs of a parallel passenger-flow network.

\section{(2) Stay arc}

A stay arc denotes the holding of a passenger at a port in a time window. A holding cost (or penalty) is the arc cost for the time window. However, if the arc just happens to connect either the departure or the arrival port of this network's corresponding OD pair, the arc cost is then zero, because, in practice, the staying of passengers at such ports is usually not considered a scheduling decision. The arc cost is adjustable. The arc flow's upper bound is the port's passenger service capacity, within the network's minimum time interval, implying that the maximum number of passengers can be accommodated at this port in the time window. The arc flow's lower bound is zero, meaning that no passenger from the corresponding OD stays at the port during this time window.

\section{(3) Demand arc}

A demand arc connects the arrival port to the departure port of this network's corresponding OD pair for a specific time interval (according to the studied ferry company, this is 30 minutes for peak hours and one hour for non-peak hours). It denotes the service demands for the OD pair for the time interval that would actually be served in the network, whether by the original ferry company or its ally. The arc cost is the negative value of the average associated ticket fare. The arc flow's upper bound is the projected demand for this OD pair. The aim of the model is to maximize the profit, which means that not all passengers for this OD pair will necessarily be served. The arc flow's lower bound is zero, meaning that none of the OD pair's passengers are served. According to Yan and Tseng [18], the trip demand for a specific OD pair can be flexibly divided into several demand arcs, based on the actual demand distribution, market characteristics, and ferry company considerations. In particular, a demand arc denotes the time interval within which passengers will wait for transportation, so there will be no significant loss. In 
other words, the projected demand for the time interval is insensitive to the associated time length. This time interval, which is determined by the carrier, is based on practical experience/judgment, and can be reset. The model can then be rerun until satisfactory results are obtained. Note that demand arc time intervals for peak/ non-peak hours and for different ODs can be different. Such a design more effectively models passenger transport plans, particularly for multi-stop trips, than does the traditional timetable drafting approach. The effectiveness depends on the setting of the demand arcs by the carrier. Finally, if the model results are expected to have an impact on the original demand, the inputs can be changed and the model rerun, until satisfactory results are acquired.

\section{Notations of symbols used in the model formulation}

Before introducing the model formulation, we first list the symbol notations that will be used in the model formulation.
$r, q \quad$ :the $\mathrm{r}^{\text {th }}$ and the $\mathrm{q}^{\text {th }}$ allied ferry companies, respectively;

$R \quad$ : the set of all allied ferry companies. In this research, $R=\{r, q\}$;

$n \quad:$ the $\mathrm{n}^{\text {th }}$ OD pair;

$o \quad: \quad$ the $o^{\text {th }}$ individual OD pair;

$a \quad:$ the $\mathrm{a}^{\text {th }}$ parallel OD pair;

$m \quad$ : the $\mathrm{m}^{\text {th }}$ complementary OD pair;

$N^{r} \quad:$ the set of all ODs for the $\mathrm{r}^{\text {th }}$ allied ferry company;

$P N^{r} \quad$ : the set of all parallel alliance passenger-flow networks for the $\mathrm{r}^{\text {th }}$ allied ferry company;

$C P N$ : the set of all complementary alliance passenger-flow networks for all allied ferry companies;

$I P N^{r} \quad$ : the set of the individual passenger-flow networks for the $\mathrm{r}^{\text {th }}$ allied ferry company;

$A^{r}, N F^{r}$ : the set of all arcs and nodes in the ferry-flow network for the $\mathrm{r}^{\text {th }}$ allied ferry company;

$C F^{r} \quad$ : the set of all cycle arcs in the ferry-flow network for the $\mathrm{r}^{\text {th }}$ allied ferry company;

$B^{n r}, N P^{n r} \quad$ : the set of all arcs and nodes in the $\mathrm{n}^{\text {th }}$ passenger-flow network for the $\mathrm{r}^{\text {th }}$ allied ferry company;

$A F^{r} \quad$ : the number of available ferry boats used to provide services for the $\mathrm{r}^{\text {th }}$ allied ferry company;

$F F^{r} \quad$ : the set of all service arcs in the ferry-flow network for the $\mathrm{r}^{\text {th }}$ allied ferry company;

$I F F^{r} \quad$ : the set of all service arcs in the ferry-flow network for the $\mathrm{r}^{\text {th }}$ allied ferry company, associated with the ferry trips served by the ferry company itself;

$P F F^{r} \quad$ : the set of all service arcs, assocaited with parallel alliance, in the ferry-flow network for the $\mathrm{r}^{\text {th }}$ allied ferry company;

$P P F A^{a r}$ : the set of the delivery arcs in the $\mathrm{a}^{\text {th }}$ parallel alliance passenger-flow network for the $r^{\text {th }}$ allied ferry company;

$C P F A^{m}$ : the set of the delivery arcs in the $\mathrm{m}^{\text {th }}$ complementary alliance passenger-flow network;

$I P F A^{\text {or }}$ : the set of the delivery arcs in the $\mathrm{o}^{\text {th }}$ individual passenger-flow network for the $\mathrm{r}^{\text {th }}$ allied ferry company;

$P P D A^{a r}$ : the set of the demand arcs in the $\mathrm{a}^{\text {th }}$ parallel alliance passenger-flow network for the $\mathrm{r}^{\text {th }}$ allied ferry company;

$C P D A^{m}$ : the set of the demand arcs in the $\mathrm{m}^{\text {th }}$ complementary alliance passenger-flow network;

$I P D A^{\text {or }}$ : the set of the demand arcs in the $\mathrm{o}^{\text {th }}$ individual passenger-flow network for the $\mathrm{r}^{\text {th }}$ allied ferry company;

$K \quad$ : the ferry boat capacity (perhaps with a planning load factor);

$F U_{i j}^{r} \quad:$ the $\operatorname{arc}(\mathrm{i}, \mathrm{j})$ flow's upper bound in the ferryflow network for the $\mathrm{r}^{\text {th }}$ allied ferry company;

$P U_{i j}^{n r} \quad:$ the $\operatorname{arc}(\mathrm{i}, \mathrm{j})$ flow's upper bound in the $\mathrm{n}^{\text {th }}$ passenger-flow network for the $\mathrm{r}^{\text {th }}$ allied ferry company;

$C_{i j}^{r} \quad:$ the $\operatorname{arc}(\mathrm{i}, \mathrm{j})$ cost in the ferry-flow network for the $\mathrm{r}^{\text {th }}$ allied ferry company;

$T_{i j}^{n r} \quad:$ the $\operatorname{arc}(\mathrm{i}, \mathrm{j})$ cost in the $\mathrm{n}^{\text {th }}$ passenger-flow network for the $\mathrm{r}^{\text {th }}$ allied ferry company;

$V C_{i j}^{n r} \quad:$ the delivery $\operatorname{arc}(\mathrm{i}, \mathrm{j}) \operatorname{cost}$ in the $\mathrm{n}^{\text {th }}$ passengerflow network for the $\mathrm{r}^{\text {th }}$ allied ferry company, associated with a ferry boat served by the ferry company itself, which is a variable cost incurred by the $\mathrm{r}^{\text {th }}$ allied ferry company for delivering a passenger;

$C V C_{i j}^{n} \quad:$ the delivery $\operatorname{arc}(\mathrm{i}, \mathrm{j})$ cost in the $\mathrm{m}^{\text {th }}$ complementary passenger-flow network, associated with the ferry boat served by the ferry company itself and its ally, which is a variable cost incurred by the ferry companies for delivering a passenger;

$P P D C_{i j}^{a r}:$ the delivery $\operatorname{arc}(\mathrm{i}, \mathrm{j}) \cos$ in the $\mathrm{a}^{\text {th }}$ parallel alliance passenger-flow network for the $\mathrm{r}^{\text {th }}$ allied ferry company, which is the cost that the $\mathrm{r}^{\text {th }}$ allied ferry company pays to the other allied ferry company for compensating its delivery of a passenger;

$D_{i j}^{m} \quad:$ the projected passenger trip demand associated with the demand arc $(i, j)$ in the $m^{\text {th }}$ complementary alliance passenger-flow network. Note that the demand is served by complementary trips of both ferry companies; 
$P T^{r} \quad$ : the proportion of profit (revenue minus variable cost for serving passengers) shared by the $\mathrm{r}^{\text {th }}$ allied ferry company under a complementary alliance, which is determined in advance through an agreement between both ferry companies. Note that the sum of all the proportions is equal to 1 , namely $\sum P T^{r}=1$.

$f_{i j}^{r} \quad:$ the $\operatorname{arc}(\mathrm{i}, \mathrm{j})$ flow in the ferry-flow network for the $\mathrm{r}^{\text {th }}$ allied ferry company;

$p_{i j}^{n r} \quad:$ the $\operatorname{arc}(\mathrm{i}, \mathrm{j})$ flow in the $\mathrm{n}^{\text {th }}$ passenger-flow network for the $\mathrm{r}^{\text {th }}$ allied ferry companies;

\section{Basic model formulation}

Besides the ferry-flow and the passenger-flow networks introduced above, there are several issues that need to be considered in the modeling: (1) the number of required ferry boats in the network should not exceed the number of available ferry boats, (2) the number of passengers transported on a ferry trip should not exceed the serving ferry boat's capacity, (3) the passenger demand served by both ferry companies should not exceed the projected one, and (4) given a parallel alliance the same service arc can be served at most once in both ferry-flow networks. Therefore, four corresponding types of side constraints are designed during the problem formulation: (1) the sum of the cycle arc flows in each ferry-flow network should not be greater than the number of available ferry boats, (2) the sum of all transport arc flows corresponding to the same service arc should not exceed the sum of each service arc flow multiplied by the ferry boat capacity, (3) each demand arc flow in the complementary alliance passenger-flow networks should be less than or equal to the associated projected passenger demand and (4) the sum of all the arc flows in the two parallel alliance ferry-flow networks, corresponding to the same ferry trip, should be less than or equal to one.

Based on the ferry-flow and the passenger-flow networks, as well as the side constraints, we formulate the model as a mixed integer network flow problem. The objective of this model is to "flow" the ferry boats and passengers simultaneously in all networks at a minimum cost. Since the ticket revenue from the passenger-flow networks is in the form of a negative cost, this objective is equivalent to the maximization of profit. The model is formulated as follows:

\section{Minimize}

$Z=\sum_{r} \sum_{i j \in A} C_{i j}^{r} f_{i j}^{r}+\sum_{r} \sum_{n} \sum_{i j \in B} T_{i j}^{n r} p_{i j}^{n r}$

$$
\begin{aligned}
& \sum_{j \in N F^{r}} f_{i j}^{r}-\sum_{k \in N F^{r}} f_{k i}^{r}=0 \\
& \forall i \in N F^{r}, \forall r \in R \\
& \sum_{j \in N P} p_{i j}^{n r}-\sum_{k \in N P} p_{k i}^{n r}=0 \\
& \forall i \in N P^{n r}, \forall n \in N^{r}, \forall r \in R \\
& \sum_{i j \in C F^{r}} f_{i j}^{r} \leq A F^{r} \quad \forall r \in R \\
& \sum_{n \in F} p_{i j}^{n r}+\sum_{m \in C P N} p_{i j}^{m} \leq K f_{i j}^{r} \\
& \forall i j \in I F F^{r}, \forall r \in R \\
& \sum_{n \in N} p_{i j}^{n r}+\sum_{n \in N} p_{i j}^{n q} \leq K f_{i j}^{r} \\
& \forall i j \in F F^{r} \backslash F F^{r}, \forall r \in R \\
& p_{i j}^{m} \leq D_{i j}^{m} \quad \forall i j \in C P D A^{m}, \forall m \in C P N \\
& \sum_{r} f_{i j}^{r} \leq 1 \quad \forall i j \in \bigcup_{r} P F F^{r} \\
& 0 \leq f_{i j}^{r} \leq F U_{i j}^{r} \quad \forall i j \in A^{r}, \forall r \in R \\
& 0 \leq p_{i j}^{n r} \leq P U_{i j}^{n r} \quad \forall i j \in B^{n r}, \forall n \in N^{r}, \forall r \in R \\
& f_{i j}^{r} \in I \quad \forall i j \in A^{r}, \forall r \in R
\end{aligned}
$$

The model is formulated as a mixed integer multiple commodity network flow problem, in which the objective function, Eq. (1), is to minimize the total system cost of the allied ferry companies. Constraints (2) and (3) ensure flow conservation at every node in each ferry/passenger-flow network. Constraint (4) denotes that the number of ferry boats used in each ferryflow network should not exceed the available number of ferry boats. Constraint (5) keeps the passenger transport volume, including the overall number of individual and complementary passengers served, within the ferry boat's carrying capacity for the ferry trips served by the ferry company itself. Eq. (6) keeps the passenger transport volume within the ferry boat's carrying capacity for the ferry trips serving both a ferry company's and its ally's passengers. Note that $R=\{r, q\}$. Eq. (7) indicates

Subject to 
that, each demand arc flow in the complementary alliance passenger-flow networks should be less than or equal to the associated projected passenger demand. Constraint (8) indicates that under the parallel alliance, the allied ferry companies should simultaneously provide at most one ferry trip. Constraints (9) and (10) hold all the arc flows within their bounds. Eq. (11) ensures the integrality of the ferry flows. It should be noted that the carriers could slightly adjust the individual model solutions, by a post optimization analysis, to better match real requirements.

Also note that for ease of comparing the performance before and after they entered into alliances, we need to calculate their individual operating profit (which is equal to the revenue minus the cost) for short term operations, for each allied ferry company. Namely the Eq. (1) could be subdivided for two allied ferry companies. Suppose that $z^{r}, F_{\text {cost }}^{r}$ and $F_{\text {rev }}^{r}$ represent the $\mathrm{r}^{\text {th }}$ allied ferry company's profit, cost and revenue, respectively. The cost and revenue are divided into three parts, parallel networks, complementary networks, and individual networks, as shown in Eqs. (12) and (13), respectively.

In Eq. (12), the first term is the ferry flow cost, the second is a variable passenger serving cost paid by the ferry company itself, under a parallel alliance, the third is a variable cost for serving its ally's passengers, under a parallel alliance, the fourth is the cost for the ferry company pays to its ally to compensate for the delivery of passengers, under a parallel alliance, the fifth is a variable cost for serving passengers, under a complementary alliance, and the last is a variable cost for serving passengers paid by the ferry company itself, in its own individual networks.

$$
\begin{aligned}
F_{\text {cos } t}^{r} & =\sum_{i j \in A} C_{i j}^{r} f_{i j}^{r}+\sum_{a \in P N^{r}} \sum_{i j \in P P F A} V C_{i j}^{a r} p_{i j}^{a r} \\
& +\sum_{a \in P N^{r} \cap P N} q_{i j} \sum_{i j P A} V C_{i j}^{a r} p_{i j}^{a q} \\
& +\sum_{a \in P N^{r}} \sum_{i j \in P P F A} P P D C_{i j}^{a r} p_{i j}^{a r} \\
& +P T^{r} \times \sum_{m \in C P N_{i j}} \sum_{C P F A} C V C_{i j}^{m} p_{i j}^{m} \\
& +\sum_{o \in I P N^{r}} \sum_{i j \in I P F A} V C_{i j}^{o r} p_{i j}^{o r}
\end{aligned}
$$

In Eq. (13), the first term is the revenue received by the ferry company itself for serving passengers, under a parallel alliance, the second is the revenue received from its ally for serving the allied ferry company passengers, under a parallel alliance, the third is the revenue for serving passengers, under a complementary alliance, and the last is the revenue received by the ferry company for serving passengers in its own individual networks. Note that, since the revenue from the passenger-flow networks is in the form of a negative cost, a minus sign to the four terms is added to transfer the value into positive revenue.

$$
\begin{aligned}
F_{r e v}^{r} & =-\sum_{a \in P N^{r}} \sum_{i j} \in P P D A \\
& \sum_{a \in} T_{i j}^{a r} p_{i j}^{a r} \\
& -P T^{r} \times \sum_{m \in C P} \sum_{i j} \sum_{i j} \sum_{i j \in C P A} P P D C_{i j}^{a q} p_{i j}^{a q} \\
& -\sum_{o \in I P N} T_{i j}^{m} p_{i j}^{m} \sum_{i j} T_{i j} T_{i j}^{o r} p_{i j}^{o r}
\end{aligned}
$$

\section{Strategic model formulations}

In this research parallel and complementary alliances are modeled simultaneously. However, in practice, the alliance type is dependent upon the nature of the allied routes. In other words, parallel and complementary alliances may not be simultaneous in all cases. However, the basic model can be suitably modified to conform to real practices. In particular, the basic model can be simplified to model either parallel or complementary alliance along. The detailed modeling of the above two modifications are now described:

\section{(1) Parallel alliance}

Each ferry company's complementary alliance passenger-flow networks are removed. The service arcs in both ferry-flow networks not serving any demand are removed. The ferry boat loading constraint (5) is modified as $\sum_{n \in N} r p_{i j}^{n r} \leq K f_{i j}^{r}, \forall i j \in I F F^{r}, \forall r \in R$, to remove all passenger flows in the complementary passenger-flow networks. Constraint (7) is removed. Note that it is assumed that additional trips of both ferry companies are constructed in the complementary network. Without the complementary alliance, these trips would not be served by either ferry company. The resulting model is thus a parallel alliance scheduling model.

\section{(2) Complementary alliance}

The parallel alliance passenger-flow networks are modified by the removal of transport arcs served by the allied ferry company to become individual passengerflow networks. The associated OD demands should then be modified (in general, they are reduced), for each ferry company. The ferry boat loading constraint (6) is removed. The bundle constraint (8) is removed. After these modifications, we construct a complementary alliance scheduling model. 


\section{Model Applications}

Although the models could be applied in many different situations, to save space, two examples are addressed below:

\section{(1) Feasibility of alliance}

Generally, the ferry companies use the maximum profit for their operation objective. If each ferry company does not allow its short-term operating profit less than a target value after alliance, then an additional constraint should be added into the basic model for this concern. Let $Z^{r}$ be the negative value of the $\mathrm{r}^{\text {th }}$ allied ferry company's profit after alliance, and $P F^{r}$ be the negative value of the $\mathrm{r}^{\text {th }}$ allied ferry company's target profit. The additional constraint is as follows:

$$
Z^{r}=\sum_{i j \in A^{r}} C_{i j}^{r} f_{i j}^{r}+\sum_{n} \sum_{i j \in B} T_{i j}^{n r} p_{i j}^{n r} \leq P F^{r} \quad \forall r \in R
$$

Note that the model could be infeasible with too large target profits for the allied ferry companies. That is, with the coordinated scheduling optimization it still cannot help the allied ferry companies achieve their target profits. Under this circumstance, the ferry companies should adjust their target profits and resolve their schedule to obtain a result satisfactory to both. During the process, each allied ferry company can also examine the alliance effect to itself that would help adjust its alliance decision in the future.

\section{(2) Minimum number of trips}

The above models were designed without specifying a minimum number of ferry trips for any OD pair. However, if the number of trips for some OD pairs in the coordinated schedule decrease enough to cause the level of service and the associated demand to drop, then the constraint for a minimum number of trips for the associated OD pairs can be introduced. For example, let $O F_{s t}^{r}$ be the number of the direct trips for the $\mathrm{st}^{\text {th }} \mathrm{OD}$ pair of the rth allied ferry company before they enter into an alliance. Also let $A_{s t}^{r}$ be the set of all direct service arcs associated with the the $\mathrm{st}^{\text {th }}$ OD pair in the $\mathrm{r}^{\text {th }}$ ferry-flow. Then, the additional constraints for each allied ferry company may now be added as follows:

$$
\sum_{i j \in A_{s t}^{r}} f_{i j}^{r} \geq O F_{s t}^{r} \quad \text { for some } s t \in N^{r}, r \in R
$$

\section{NUMERICAL TESTS}

To test how well the models may be applied in the real world, we performed numerical tests using operating data from two Taiwan ferry companies, with reasonable assumptions. We used the $\mathrm{C}$ computer language, coupled with the mathematical programming solver, CPLEX 9.0, to build the model and to solve the problems. The tests were performed on a Pentium $4-2.0 \mathrm{G}$ with 1 . $5 \mathrm{~Gb}$ of RAM in the environment of Microsoft Windows XP. We first used the operating data to build the model, and then solved the problems. Finally, we demonstrated several examples for how to apply the models.

\section{Data analysis and Test results}

The numerical tests were mainly based on the weekday data obtained from two Taiwan ferry company operations (Ferry companies A and B) during September of 2005, with reasonable simplifications. Five ports were served by Ferry companies A and B, each with a single fleet of 8 ferry boats. Each ferry boat has a carrying capacity of 95 seats. To preliminarily evaluate the model performance, the projected OD demand (for individual, parallel and complementary OD pairs) was estimated with reasonable assumptions. In particular, for individual OD pairs and parallel OD pairs, the projected OD demands mainly referred to the related reports of the two ferry companies. For complementary OD pairs, the projected OD demands, which were newly developed, were directly set based on planning staff experiences of the two ferry companies. All the cost parameters and other inputs, such as the trip time, the distance between two ports, and the berthing time, are primarily based on actual operating data, with reasonable simplifications. Moreover, for the parallel alliance, the cost that a ferry company must pay to its allies, to compensate for the transport of a passenger, is set as ninety percent of the ticket fare. For the complementary alliance, according to real practice, the proportion of the profit is set to be 0.5 for both ferry companies (i.e. $P T^{r}$ $=0.5$ ). Note that the fixed cost (i.e., the sunk cost) and the indirect cost (for example, the capital investment, depreciation, maintenance or rental charges), which are constant in short-term operations, are not included in the model. In other words, the profit calculated here is the short-term "operating profit", rather than the actual overall profit of the system. However, the optimization of the short-term profit can increase the long-term system profit. In addition, to preliminarily evaluate the proposed models, the current schedules of the two ferry companies (parallel alliance) obtained by the trial-anderror experience-based method are used. These results obtained are referred to as "actual operations". In 
accordance with real practices, the results obtained by the parallel alliance model, with the same projected demand as for actual operations, are compared with that of the actual operations.

As shown in Table 1, the objective value (OBJ) of the parallel alliance was better than that of actual operations by $1.07 \%$, showing that from a systematic optimization perspective the parallel alliance model is superior to the current trial-and-error experience-based method. Moreover, compared with the individual ferry company's objective values of actual operations, using the parallel alliance model, the objective value of Ferry company A increased from -111600.32 to -112963.58 (an improvement of $1.22 \%$ ), and the objective value of Ferry company B increased from -131740.58 to -132982 . 57 (an improvement of $0.94 \%$ ). In addition, with the use of the parallel alliances model the frequency (trips/day) for both ferry companies increased (from 227 to 231 for A and from 242 to 245 for B). Similarly, the service rates for both ferry companies increased (from $94.7 \%$ to $97.4 \%$ for A and from $96.2 \%$ to $97.9 \%$ for B). The average load factors for both ferry companies also increased (from $83.5 \%$ to $84.69 \%$ for A and from $84.9 \%$ to $85.57 \%$ for B). All of the results show that the parallel alliance model could improve over the current trial-anderror method used in actual operations.

In addition to the above comparison, we also compared the results of different alliance type operations with those of the individual operations. Note that when the projected OD demand for a parallel OD pair is separated into two individual ones, then according to staff experience the demand will be suitably reduced. The results are shown in Table 2. Note that the term "mixed alliance" denotes the combination of both parallel and complementary alliances. The best solution was yielded by the mixed alliance, with an objective value of -247072.75 . The parallel alliance was next, with an objective value of -245946.15 , followed by the complementary alliance with an objective value of 243908.87. The individual operations performed most poorly, with an objective value of $-242884.01(-111490$. 43 and -131393.58 for Ferry companies A and B). From the above results, we found that the mixed alliance integrated not only the parallel routes but also connected the complementary routes, and was therefore better than the parallel alliance and the complementary one, respectively. In addition, the parallel alliance is more effective than the complementary one. It is also

Table 1. Test results for actual operations and parallel alliance

\begin{tabular}{|c|c|c|c|c|}
\hline & \multicolumn{2}{|c|}{ Actual operations } & \multicolumn{2}{|c|}{ Parallel alliance } \\
\hline & $\begin{array}{c}\text { Ferry } \\
\text { company A }\end{array}$ & $\begin{array}{c}\text { Ferry } \\
\text { company B }\end{array}$ & $\begin{array}{c}\text { Ferry } \\
\text { company A }\end{array}$ & $\begin{array}{c}\text { Ferry } \\
\text { company B }\end{array}$ \\
\hline \multirow{2}{*}{ OBJ (NT\$) } & \multicolumn{2}{|c|}{-243340.9} & \multicolumn{2}{|c|}{-245946.15} \\
\hline & -111600.32 & -131740.58 & -112963.58 & -132982.57 \\
\hline Computation time (sec) & \multicolumn{2}{|c|}{ NA } & \multicolumn{2}{|c|}{359.36} \\
\hline Ferry size & 8 & 8 & 8 & 8 \\
\hline Frequency (trips/day) & 227 & 242 & 231 & 245 \\
\hline Service rate $(\%)$ & 94.7 & 96.2 & 97.4 & 97.9 \\
\hline Average load factor $(\%)$ & 83.5 & 84.9 & 84.69 & 85.57 \\
\hline
\end{tabular}

Table 2. Test results

\begin{tabular}{|c|c|c|c|c|c|c|c|c|}
\hline & \multicolumn{2}{|c|}{ Individual operations } & \multicolumn{2}{|c|}{ Parallel alliance } & \multicolumn{2}{|c|}{ Complementary alliance } & \multicolumn{2}{|c|}{ Mix alliance } \\
\hline & $\begin{array}{c}\text { Ferry } \\
\text { company A }\end{array}$ & $\begin{array}{c}\text { Ferry } \\
\text { company B }\end{array}$ & $\begin{array}{c}\text { Ferry } \\
\text { company A }\end{array}$ & $\begin{array}{c}\text { Ferry } \\
\text { company B }\end{array}$ & $\begin{array}{c}\text { Ferry } \\
\text { company A }\end{array}$ & $\begin{array}{c}\text { Ferry } \\
\text { company B }\end{array}$ & $\begin{array}{c}\text { Ferry } \\
\text { company A }\end{array}$ & $\begin{array}{c}\text { Ferry } \\
\text { company B }\end{array}$ \\
\hline \multirow{2}{*}{ OBJ (NT\$) } & \multirow{2}{*}{-111490.43} & \multirow{2}{*}{-131393.58} & \multicolumn{2}{|c|}{-245946.15} & \multicolumn{2}{|c|}{-243908.87} & \multicolumn{2}{|c|}{-247072.75} \\
\hline & & & -112963.58 & -132982.57 & -111983.51 & -131925.36 & -113224.32 & -133848.43 \\
\hline Computation time (sec) & 123.15 & 142 & \multicolumn{2}{|c|}{359.36} & \multicolumn{2}{|c|}{395.47} & \multicolumn{2}{|c|}{376.32} \\
\hline Ferry size & 8 & 8 & 8 & 8 & 8 & 8 & 8 & 8 \\
\hline Frequency (trips/day) & 226 & 241 & 231 & 245 & 230 & 244 & 235 & 248 \\
\hline Service rate $(\%)$ & 94.9 & 96.3 & 97.4 & 97.9 & 97.1 & 97.8 & 97.6 & 98.2 \\
\hline Average load factor (\%) & 83.6 & 84.96 & 84.69 & 85.57 & 84.23 & 85.27 & 85.08 & 86.12 \\
\hline
\end{tabular}


found that compared with the individual ferry company's objective values, with a mixed alliance, the objective value of Ferry company A increased from -111490.43 to -113224.32 (an improvement of $1.55 \%$ ), and the objective value of Ferry company B increased from -131393. 58 to -133848.43 (an improvement of $1.86 \%$ ). For a parallel alliance, the objective value of Ferry company A increased from -111490.43 to -112963.58 (an improvement of $1.32 \%$ ), and the objective value of Ferry company B increased from -131393.58 to -132982.57 (an improvement of $1.21 \%$ ). For a complementary alliance, the objective value of Ferry company A increased from -111490.43 to -111983.51 (an improvement of $0.44 \%$ ), and the objective value of Ferry company B increased from -131393.58 to -131925.36 (an improvement of $0.405 \%$ ). The above results show these types of alliance do improve ferry company operations.

In Table 2, the available ferry boats of both ferry companies ( 8 of $\mathrm{A}$ and 8 of $\mathrm{B}$ ) are all used up. In addition, the frequency (trips/day) for both ferry companies increased for the complementary, the parallel and the mixed alliances, respectively (for A from 226 to 230, 231 and 235; and for B from 241 to 244, 245 and 248). Similarly, the service rates for both ferry companies increased, for the complementary, parallel and mixed alliances (for A from $94.9 \%$ to $97.1 \%, 97.4 \%$ and $97.6 \%$, respectively; and for B from $96.3 \%$ to $97.8 \%$, $97.9 \%$ and $98.2 \%$, respectively). The average load factors for both ferry companies, for the complementary, the parallel and the mixed alliance, also increased (for A from $83.6 \%$ to $84.23 \%, 84.69 \%$ and $85.08 \%$, respectively; and for B from $84.96 \%$ to $85.27 \%, 85.57 \%$ and $86.12 \%$, respectively). The above results showed that the operations of two ferry companies were all improved, irregardless of the alliance types. In particular, alliances through complicated combinatorial optimization, especially the mixed type of alliance, can lead to the effective integration of ferry fleet routes and schedules and hence the improvement of the ferry company operations.

Finally, the ferry fleet flows obtained above could not yet be directly put into practice without identifying each ferry boat path in the ferry-flow networks. The flow decomposition method [19] was applied to trace the path of each ferry boat. An example of the ferry boat routes is shown in Figure 6, the full lines represent a ferry company A's ferry boat route and the dotted lines represent a ferry company B's ferry boat route.

\section{Model Applications/Scenario analyses}

For brevity, we use the mixed alliance model to demonstrate some model applications. Furthermore, to evaluate the model performance for solving middle/

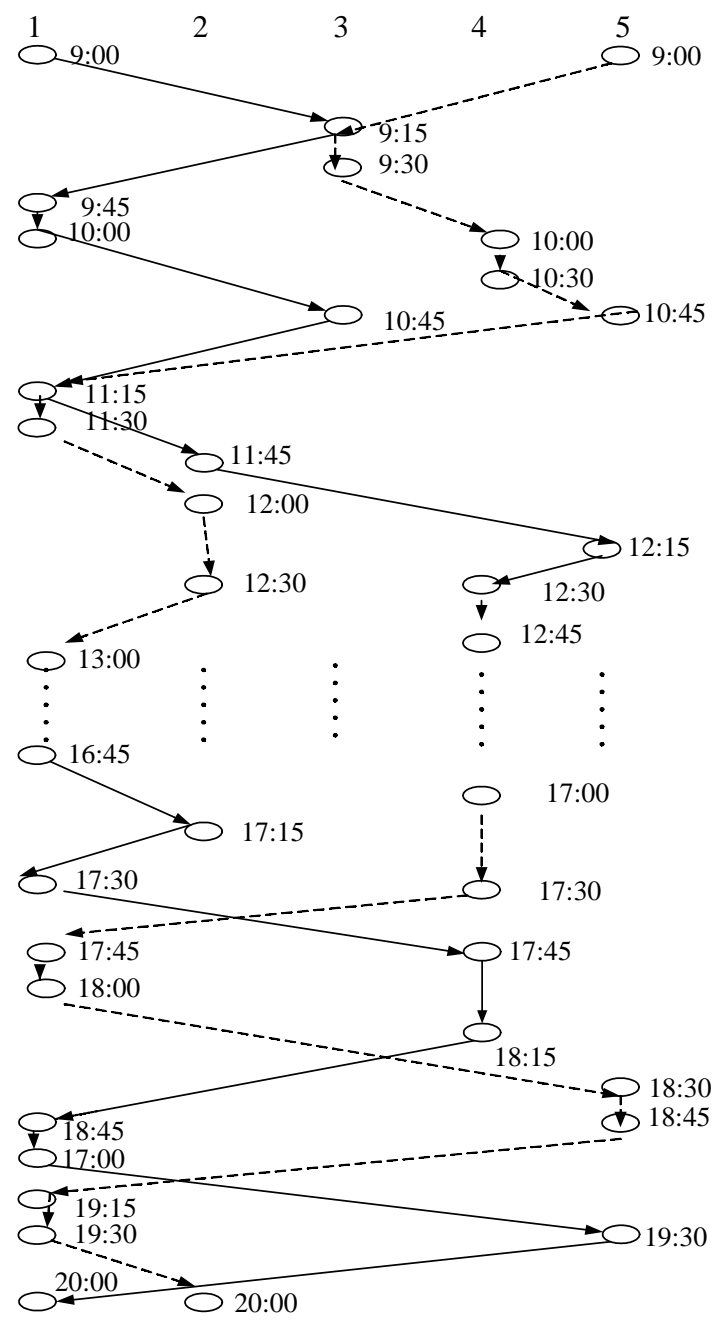

Fig. 6. An example of ferry boat routes.

large scale problems, we also performed a scenario analysis.

\section{(1) Feasibility of alliance}

In practice, the ferry companies may consider the alliance feasibility to themselves. To demonstrate the applications, we solved the problem incorporating the alliance feasibility of target profit. Assume the target profit for each ferry company after the alliance to be 1.015 times of that without the alliance (i.e., $P F^{1}=$ $1.015 *(-111600.32)$ and $\left.P F^{2}=1.015 *(-131740.58)\right)$. We added the associated constraint with the alliance feasibility into the model and then solved the problem. As shown in Table 3 , the total objective value slightly increased from -247072.75 to -247050.7 (an increase of $0.009 \%$ ), due to the additional constraint. Both ferry companies reached their target profits, with -113290.19 $(=1.01514 *(-111600.32)<1.015 *(-111600.32))$ and 
$-133760.51(=1.01533 *(-131740.58)<1.015 *$ $(-131740.58))$, respectively, implying that this application can help the allied ferry companies make suitable schedules for achieving their target profits.

\section{(2) Minimum number of trips}

In this scenario, we assume that after the alliance the number of trips for each ferry company decreased for one individual OD pair, causing the levels of service to drop. It is determined to maintain a minimum number of trips (for example, considering the long term operation strategy), equal to their original number before the alliance for these two individual OD pairs (i.e., 22 trips per day for Ferry company A and 23 trips per day for Ferry company B). Therefore, two more side constaints are added, as in Eq. (13). We rerun the model with the other inputs remaining the same. The results are shown in Table 4. Although the results show that the profits of Ferry companies A and B decreased by 36.93 and 25.86, respectively, the levels of services were maintained. Note that Ferry company A removes 1 trip and Ferry company B 1 trip, because, for the system optimization

Table 3. Test results for the alliance feasibility

\begin{tabular}{lcc}
\hline & \multicolumn{2}{c}{ Mix alliances } \\
\cline { 2 - 3 } & Ferry & Ferry \\
& company A & company B \\
\hline OBJ (NT\$) & \multicolumn{3}{c}{-247050.7} \\
GAP (\%) & -113290.19 & -133760.51 \\
Computation time (sec) & \multicolumn{3}{c}{0.115} \\
Ferry size & \multicolumn{3}{c}{576.32} \\
Frequency (trips/day) & 236 & 8 \\
Service rate (\%) & 97.65 & 247 \\
Average load factor (\%) & 85.11 & 86.17 \\
\hline
\end{tabular}

perspective under limited resources, increasing the number of trips for the two OD pairs would decrease the number of trips for all other OD pairs.

\section{(3) Problem scales}

To evaluate the model performance for middle/ large scale problems, we tested 3 more problem instances with different scales ranging from 2 to 4 times the original scale. For each problem instance, we added a number of ports, ferry boats and OD pairs to our original problem. The distance, trip times and ticket fares for each new port-pair, the berthing time at each new port, and other cost parameters were randomly set in relation to the original problem. Based on the original OD demands, as well as the original/new ferry fleet size, we randomly set the trip demand for each OD pair. In particular, the trip demand for each OD pair was suitably increased with the ferry fleet size. The parameters, CPLEX 9.0 and the test environment were set the same as in the previous test. Table 5 shows the test results for different problem instances. As the problem scales increased, the computation time

Table 4. Test results for minimum number of trips

\begin{tabular}{lcc}
\hline & \multicolumn{2}{c}{ Mix alliances } \\
\cline { 2 - 3 } & Ferry & $\begin{array}{c}\text { Ferry } \\
\text { company A }\end{array}$ \\
& \multicolumn{2}{c}{-247009.96} \\
\hline OBJ (NT\$) & -113187.39 & -133822.57 \\
GAP (\%) & \multicolumn{3}{c}{0.039} \\
Computation time (sec) & \multicolumn{3}{c}{426.55} \\
Ferry size & 8 & 8 \\
Frequency (trips/day) & 234 & 247 \\
Service rate (\%) & 97.61 & 98.22 \\
Average load factor $(\%)$ & 85.06 & 86.11 \\
\hline
\end{tabular}

Table 5. Test results for problem scales

\begin{tabular}{|c|c|c|c|c|c|c|c|c|}
\hline & \multicolumn{2}{|c|}{$\begin{array}{l}\text { Original } \\
(5 \text { ports })\end{array}$} & \multicolumn{2}{|c|}{$\begin{array}{c}2 \text { times } \\
\text { (10 ports) }\end{array}$} & \multicolumn{2}{|c|}{$\begin{array}{c}3 \text { times } \\
\text { (15 ports) }\end{array}$} & \multicolumn{2}{|c|}{$\begin{array}{l}4 \text { times } \\
\text { (20 ports) }\end{array}$} \\
\hline OBJ (NT\$) & \multicolumn{2}{|c|}{-247072.75} & \multicolumn{2}{|c|}{-544862.33} & \multicolumn{2}{|c|}{-914562.49} & \multicolumn{2}{|c|}{-1314944.15} \\
\hline $\operatorname{GAP}(\%)$ & \multicolumn{2}{|c|}{0.205} & \multicolumn{2}{|c|}{0.201} & \multicolumn{2}{|c|}{0.102} & \multicolumn{2}{|c|}{0.23} \\
\hline Computation time (sec) & \multicolumn{2}{|c|}{376.32} & \multicolumn{2}{|c|}{571.97} & \multicolumn{2}{|c|}{863.22} & \multicolumn{2}{|c|}{1348.39} \\
\hline OD pairs & 12 & 12 & 24 & 24 & 36 & 36 & 48 & 48 \\
\hline Ferry fleet size & 8 & 8 & 16 & 16 & 24 & 24 & 32 & 32 \\
\hline Frequency (trips/day) & 235 & 248 & 476 & 499 & 701 & 745 & 937 & 990 \\
\hline Service rate $(\%)$ & 97.6 & 98.2 & 97.33 & 98.16 & 97.45 & 98.24 & 97.49 & 98.17 \\
\hline Average load factor $(\%)$ & 85.08 & 86.12 & 84.91 & 86.08 & 85.03 & 86.11 & 85.09 & 86.13 \\
\hline
\end{tabular}


increased. For example, a mixed alliance with 20 ports, 48 OD pairs and 32 ferry boats for each ferry company required a computation time of 1348.39 seconds (3.58 times the original one). This shows the model's efficiency for large-scale problems. To save space, the reader may contact the authors for the detailed results that are not discussed here.

\section{CONCLUSIONS}

In this research, we develop several coordinated scheduling models designed to help the participating ferry companies solve for the most satisfactory ferry fleet routes and timetables under the alliance. It is expected that the models will be useful planning tools by which the allied ferry companies can determine the most suitable ferry fleet routes and timetables for shortterm operations. We employ network flow techniques to construct the models. Each model includes multiple passenger- and ferry-flow networks that can formulate the flows of passengers and allied ferry boats in the dimensions of time and space. A number of side constraints are set according to real operating requirements. The models are formulated as multiple commodity network flow problems which are solved using a mathematical programming solver.

Numerical tests utilizing the domestic operations of two ferry companies in Danshui were performed to preliminarily evaluate the models. The results show that the coordinated type of alliance not only reduces the operating cost but also increases profit. The mixed type of alliance out-performs both the parallel and complementary alliance. To demonstrate how the model can be applied, we also outlined several scenarios with different conditions. Although the preliminary test results show that the models are potentially useful for scheduling, especially for domestic ferry companies, more tests or case studies should be conducted, so that carriers may grasp their limitations, before putting them to practical use. The models, the test results, and the model applications, should all be useful reference material for allied ferry companies to determine the most satisfactory short-term ferry fleet routes and schedules.

The models may also be suitably modified for alliances with more than two ferry companies. The extension of a two-ferry company alliance to a multiferry company alliance, and the incorporation of other objectives, operating constraints or alliance strategies involved in actual operations, could be directions for future research. Note that although the technique for designing demand arcs used in this research is an improvement over the traditional timetable drafting approach, the number of passengers transported may not be accurately calculated, due to the complicated passenger characteristics and choice behaviors that occur in the real market. If the provided services (including the trip frequency and the trip travel time) do not reflect the projected demand, the proposed models can be rerun, with suitable demand modification, until satisfactory results are acquired. However, if the provided services vary significantly with the demand or due to passenger characteristics and choice behaviors, then this technique might be difficult to apply in practice. The proposed models can however be suitably modified by incorporating a passenger choice model and a generalized passenger flow network, as was done in Yan et al. [20]. This could also be a direction for future research.

\section{ACKNOWLEDGEMENTS}

This research was supported by a grant from the National Science Council of Taiwan. We thank the two ferry companies for providing the test data as well as their valuable opinions.

\section{REFERENCES}

1. Barnhart, C., Kniker, T., and Lohatepanont, M., "Itinerary-Based Airline Fleet Assignment," Transportation Science, Vol. 36, No. 2, pp. 199-217 (2002).

2. Brueckner, J.K. and Whalen, W.T., "The Price Effects of International Airline Alliances," Journal of Law and Economics, Vol. 43, No. 2, pp. 503-545 (2000).

3. Cho, S.C. and Perakis, A.N., "Optimal Liner Fleet Routing Strategies," Maritime Policy and Management, Vol. 23, No. 3, pp. 249-259 (1996).

4. Christiansen, M. and Fagerholt, K., "Robust Ship Scheduling with Multiple Time Windows," Naval Research Logistics, Vol. 49, No. 6, pp. 611-625 (2002).

5. Dennis, N., "Scheduling Issues and Network Strategies for International Airline Alliances," Journal of Air Transport Management, Vol. 6, pp. 75-85 (2000).

6. Evans, N., "Collaborative Strategy: An Analysis of the Changing World of International Airline Alliances," Tourism Management, Vol. 22, pp. 229-243 (2001).

7. Fagerholt, K., "Ship Scheduling with Soft Time Windows - An Optimisation Based Approach," European Journal of Operational Research, Vol. 131, pp. 559-571 (2001).

8. Jaramillo, D.I. and Perakis, A.N., "Fleet Deployment Optimisation for Liner Shipping Part 2: Implementation and Results," Maritime Policy and Management, Vol. 18, pp. 235-262 (1991).

9. Lane, D.E., Heaver, T.D., and Uyeno, D., "Planning and Scheduling for Efficiency in Liner Shipping," Maritime Policy and Management, Vol. 14, pp. 109-125 (1987).

10. Li, M.Z.F., "Distinct Features of Lasting and Nonlasting Airline Alliances," Journal of Air Transport 
Management, Vol. 6, pp. 65-73 (2000).

11. Oum, T.H., Yu, C., Zhang, A., "Global Airline Alliances: International Regulatory Issues," Journal of Air Transport Management, Vol. 7, pp. 57-62 (2001).

12. Park, J.H. and Zhang, A., "An Empirical Analysis of Global Airline Alliances: Cases in North Atlantic Markets," Review of Industrial Organization, Vol. 16, No. 4, pp. 367-384 (2000).

13. Powell, B.J. and Perakis, A.N., "Fleet Deployment Optimisation for Liner Shipping," Maritime Policy and Management, Vol. 24, No. 2, pp. 193-211 (1997).

14. Rana, K. and Vickson, R.G., "A Model and Solution Algorithm for Optimal Routing of A Time-Chartered Containership," Transportation Science, Vol. 22, pp. 83-95 (1998).

15. Ronen, D., "Short-Term Scheduling of Vessels for Shipping Bulk or Semi-Bulk Commodities Originating in a Single Area," Operations Research, Vol. 34, No. 1, pp. 164-173 (1986).

16. Vowles, T.M., "The Geographic Effects of US Airline
Alliances," Journal of Transport Geography, Vol. 8, pp. 277-285 (2000).

17. Yan, S. and Chen, H.L., "A Scheduling Model and a Solution Algorithm for Inter-City Bus Carriers," Transportation Research, Vol. 36A, pp. 805-825 (2002).

18. Yan, S. and Tseng, C.H., "A Passenger Demand Based Model for Airline Flight Scheduling and Fleet Routing," Computers and Operations Research, Vol. 29, pp. 1559-1581 (2002).

19. Yan, S. and Young, H.F., "A Decision Support Framework for Multi-Fleet Routing and Multi-Stop Flight Scheduling," Transportation Research, Vol. 30A, pp. 379-398 (1996).

20. Yan, S., Tang, C.H., and Lee, M.C., "A Flight Scheduling Model for Taiwan Airlines under Market Competitions," Omega - International Journal of Management Science, Vol. 35, pp. 61-74 (2007).

21. Zhang, A., Hui, Y.V., and Leung, L., "Air Cargo Alliances and Competition in Passenger Markets," Transportation Research, Vol. 40E, pp. 83-100 (2004). 